\title{
Never Waste a Crisis!? - The Impact of the COVID-19 Crisis on the Mental Health of EDM DJs
}

\author{
Melanie Ptatscheck \\ Hochschule für Musik und Tanz Köln \\ melanie.ptatscheck@hfmt-koeln.de
}

\begin{abstract}
The COVID-19 crisis places an unprecedented strain on an industry already characterized by poor mental health due to challenging working conditions, including the difficulty of sustaining a living, anti-social working hours, exhaustion, and the inability to plan time and future. This article discusses the current mental health conditions of musicians in dealing with the exceptional situation through a retrospective perspective on those affected. Based on a qualitative interview study conducted with EDM DJs during the first lockdown in Germany, I use three exemplary cases to give insights into their individual experienced living environments and working conditions. I show how the COVID-19 crisis is related to their previous life situation, mental state, and personal self-perceptions as DJs. I further argue that the current crisis may not only have a negative impact on the (already poor) mental health of creative professionals but may also bring health-promoting potential.
\end{abstract}

KEYWORDS: crisis, mental health, EDM DJs, COVID-19, health resources

\section{Introduction}

The COVID-19 pandemic is considered the most pressing global challenge since World War II (Bloomsberg 2020; Sample 2020), having brought innumerable challenges to many people's lives. Although the pandemic is most notably a physical health crisis, it strongly affects mental health as well. This, according to the Academy of Science of South Africa (ASSAf) and the German National Academy of Sciences Leopoldina (2020), may relate to social isolation, job and financial losses, and uncertainty about the real impact of the crisis. These stressors can increase emotional distress and lead to mental health issues such as depression and anxiety disorder. Especially for many music professionals, the situation is currently exceptionally difficult due to the measures taken to prevent the rapid spread of COVID-19. Many artists experience existential fears, changed daily routines, and

IASPM Journal vol.11 no.1 (2021) 
high stress. The necessary measures against the pandemic, sensible as they may be, effectively function as an employment ban for many musicians, preventing them from earning a living through no fault of their own. Venues are closed, and events as well as regular commitments abruptly break away - for some, this means the loss of all sources of income. Financial concerns seem to be a key cause of mental health problems, as a recent study by Help Musicians UK (2021) has shown: The survey of 700 professional musicians revealed that ninety-six percent are worried about their financial situation, with seventy percent not confident they will be able to cope financially over the next months. The surveyed musicians described feelings of powerlessness and hopelessness since the start of the pandemic when work instantly dropped away. Ninety-one percent of musicians agree a lack of certainty about the future has had a negative effect on their mental health, and twenty-two percent were considering giving up the profession for good.

"The pandemic has tapped into a collective trauma. Something that we've never really experienced before", says Adam Ficek, psychotherapist and musician, about the exceptional situation in an interview with Pioneer DJ (2020): "this is A: universal. This is B: going to touch everyone. This is C: something that we've not really experienced before". Although the pandemic is considered an extraordinarily stressful situation that may be accompanied by negative psychological effects, for many actors in the cultural sector, a state of mental crisis is not limited to the pandemic. It is not only the virus-related crisis situation itself that leads to mental strains. Mental health concerns were already an issue within the music business before the outbreak of the pandemic. An earlier study of Help Musicians UK from 2016 found that individuals who work in the music industry are three times more likely to suffer from mental illness compared to the general public. Of 2,000 musicians surveyed, seventy-one percent describe experiencing anxiety and/or panic attacks, and sixty-nine percent experience varying degrees of depression (Gross and Musgrave 2016). These results are confirmed by the Swedish distribution service Record Union. In their 73 percent report of 2019, they found that seventythree percent of the surveyed independent musicians suffer from mental illness, which is defined as experiencing "negative emotions such as stress, anxiety and/or depression in relation to their music creation" (Record Union 2019).

Given the precarious nature of work and the 'gig economy' that is typical in the culture industries (Gross et al. 2018; Hesmondhalgh and Baker 2011), it is no surprise that the demographic of musicians are vulnerable to mental health difficulties. As shown by Sandoval (2018: 1), "the example of work in the cultural sector illustrates how passion and love for one's work often go hand in hand with rather unlovable working conditions" (see also McRobbie 2015; Hope and Richards 2015). On the one hand, Gross and Musgrave (2020: 1) describe the music industries and the wider entertainment industries that musicians inhabit as a "pleasure dome"; "a site of hedonism, enjoyment and self-actualisation, full of creativity and self-expression, excess and glamour". On the other hand, they highlight that, paradoxically, "these industries are equally full of people struggling and suffering from a variety of overlapping economic, psychological and addiction issues" (ibid.). According to Leff (2020), Senior Director at MusiCares, the list of common threads amongst (professional) musicians is long: financial instability and personal finances; lack of permanency due to travel; navigating and managing relationships with family, friends, colleagues; isolation; poor nutrition and lack of sleep; pressure to succeed and maintain a career status; perception versus reality and one's self-identity; social media scrutiny; working multiple jobs to sustain their craft; a culture of self-medication and drug/alcohol abuse; managing one's health and limited access to medical and behavioural health resources. As a result, the list 
of people with mental health problems in the music industries seems endless, and the estimated number of unreported cases confirms the "hidden crisis amongst musicians" (Help Musicians UK 2021).

Mental issues and deaths by suicide (such as those of Linkin Park's frontman Chester Bennington, the Prodigy's singer Keith Flint, or K-Pop star Goo Hara) are not only linked to the world's famous superstars, but it is often these prominent personalities who direct attention to these underrepresented issues. This is particularly pertinent in musical scenes, such as the Electronic Dance Music (EDM) (1) scene, that are considered "safe space[s] where issues or difficulties do not exist", "where it is all the time about party" (Schott 2019), which presume to be less connected to mental health issues. In terms of EDM, it was Avicii's death - and the documentary Avicii: True Stories, released by Levan Tsikurishvili (2017) shortly before the DJ's death - in particular, that highlighted the pressures of pursuing a career in EDM. His case also showed that mental disorders such as depression, anxiety, and substance abuse affect people regardless of their fame and income. In the wake of Avicii's tragedy, the mental health of EDM artists became a topic of more intense discussion, driven significantly by The Electronic Music Industry Guide to Mental Health launched by the Association for Electronic Music (AFEM), Music Managers Forum, Help Musicians UK, and Music Support in 2019, which brought the discussion about mental health into the community itself and related journalistic platforms (such as Groove Magazine, Faze Magazine, Resident Advisor or Mixmag) and academic discourses (Ptatscheck 2021; Musgrave 2020).

With the onset of the pandemic, the issue of both journalistic and scientific controversies regarding musicians' health and wellbeing now seems to have come even more into focus. Themed issues (for example, the Journal of Music, Health, and Wellbeing) and scientific platforms (for example, the Working in Music International Research Network or Musicovid) reflect on the role of music during the current health crisis. Controversies also increasingly focus on the (mental) health of creative professionals in the music business and their reflections on the current situation. While most of these disputes focus on the 'here and now,' this article aims to discuss the current mental health status of musicians and resulting behaviours in dealing with the exceptional situation through a retrospective perspective of those affected.

Located at the intersection of Popular Music Studies and Public Health and as part of a larger study, this article takes into account the impact of the COVID-19 crisis on mental health, wellbeing, and related career trajectories using the example of German EDM DJs. It represents an interdisciplinary research approach, which contributes to a growing body of literature concerning the realities of practice for creative labour(ers) and precarious conditions (for example, Sandoval 2018; Hughes et al. 2016; McRobbie 2015; Cloonan 2014; Hesmondhalgh 2011) with a focus on the state of health of musicians within the music industries (for example, Brunt and Nelligan 2020; Gross and Musgrave 2020, 2016; Gross et al. 2018). In order to gain access to the lives and (self-)perceptions of EDM DJs, I first approach the experience of crises through selected concepts in the context of psychological research. These approaches are applied to empirical material generated on the basis of narrative interviews. From a socio-psychological perspective, I argue firstly that dealing with the COVID-19 crisis is related to one's previous life situation, mental state, and thus personal self-perceptions of the 'DJ-self'. Second, I argue that the current crisis may not only have a negative impact on the (already poor) mental health of creative professionals but may also bring health-promoting potential. 


\section{Definition and Phases of Crises}

A crisis is a temporary event that results from an acute overload of a habitual behavioural and coping system due to stressful external and internal triggers (Simmich et al. 1999). In this context, the acute overstress may result from an episode of brief but severe stress, or it may be the result of a longer-lasting, cumulative stress. According to Dross (2001), from a socio-psychological point of view, a crisis can be said to have occurred when a state of psychological stress has arisen that is clearly different from normal wellbeing, is perceived as hardly bearable and leads to emotional destabilization. In light of such events, the previous habits of life as well as life goals are questioned or made impossible.

Critical life events are considered prototypical triggers for crises. These are expected or unexpected life events that are viewed by the person as incisions, transitions, or caesuras in the life course and require considerable adjustment (Filipp 1997). Critical life events cannot be solved within the framework of previous individual problem-solving strategies and lead to increased psychological lability, and psychopathological symptoms in the affected individual (Reiter and Strotzka 1977).

The COVID-19 pandemic represents a critical life event that will be conceptualized below as a traumatic or situational crisis. Cullberg (1978) defines this type of crisis as "a situation of a generally painful nature that suddenly arises due to a crisis occasion with subjective valence and that suddenly threatens psychological existence, social identity, and security" (transl. MP). Although every crisis unfolds in its own way, research has identified phases common to nearly every crisis. For this study, I refer to the phase models of Kast (2017) and Cullberg (1978), who highlight four stages of crisis management in which traumatic crises can be managed.

[1] Shock / "not wanting to admit": At the onset of the crisis situation, a "shock reaction" is triggered in those affected, lasting a few moments to days, in which tension-reducing defense mechanisms such as denial and repression predominate. Inner chaos prevails, which can express itself through apathy or complete paralysis but also through emotional outbursts or apparent functioning.

[2] Reaction: The shock reaction is followed by a "reaction phase" of days to months, in which the person concerned alternates between affective turbulence and apathy, each with severe accompanying physical symptoms. This phase carries the risk of maladaptation (for example, substance abuse), which can lead to further aggravation (for example, psychotic phase, suicidality) and chronification.

[3] Processing: Now, the exit from the crisis begins. This includes accepting the loss. At the same time, the search for solutions to cope with the crisis situation begins. At best, one succeeds in leaving the past behind and separating oneself from negative thoughts.

[4] (Re-)orientation: With appropriate processing of the crisis occasion and overcoming its consequences, the patient can enter the stage of "reorientation" and "reorganization". Often reorientation is only possible for the patient if an integration of the traumatic experience into the emotional world of the affected person takes place.

The various phases of crisis management are rarely chronological: "shock", "reaction", "processing", and "reorientation" can overlap and cannot be clearly delineated. It also happens that phases repeat themselves. It must also be taken into account that a crisis involves various "dangers": due to the high emotional adjustment, impulse breakthroughs can occur with actions that are dangerous to oneself or others; furthermore, with corresponding vulnerability, it can lead to the 
onset or recurrence of a mental disorder (especially anxiety disorders and depression). If the crisis is not dealt with adequately or at all, it can become chronic, with a permanently heightened state of tension and the resulting psychosomatic complaints (for example, sleep disorders, pain, dizziness, gastrointestinal complaints). This in turn can promote the development of maladjustment, for example a harmful use of addictive substances to relieve symptoms such as anxiety, anger, and hopelessness.

Although there is overwhelming evidence that critical life events can produce many negative physical and psychological consequences, there is a body of literature suggesting that people exposed to even the most traumatic events may perceive at least some good emerging from their struggle with such tragedies (cf. Tedeschi et al. 2018). If crisis is seen as "opportunity" or "chance of change", the term does not have an exclusive pathologizing stigma attached to it. A crisis can also be a turning point in a dangerous or unhealthy conflict situation preceded by a dysfunction. The decision-making situation associated with the turning point usually offers both the opportunity to resolve the conflicts and the possibility of exacerbating them. Therefore, crises can contribute to personal maturation and enable a reshaping of life.

\section{Individual Crisis Management}

In a sudden crisis, the main concern, especially in the beginning, is to fight the loss of control and to become master of the uncertain situation. Researchers (for example, Weick 1988) also speak of "sensemaking" here. However, the extent to which people feel a loss of control in a crisis varies from person to person. As a result, people cope with the same crisis event at different speeds and with individual strategies - while some find their way back to normality quickly, others struggle with their emotions for longer. Individual attitude, previous experiences, and the information available to a person influence the "sensemaking" in the end.

In principle, from the perspective of the individual, the crisis is an event that, to varying degrees, challenges the person's self-worth, threatens or challenges their central beliefs, interferes with their central goals and concerns, and reactivates previous unresolved events (Filipp 1997). According to Lazerus' (1999) transactional stress model, the effects of crises on the individual's state of mind and behaviour result from the subjective evaluation of the crisis occasion and the resources available. The more a situation is assessed as existentially threatening or dangerous, and the lower the perceived chances of success in enduring or coping with the crisis, the more the reaction of those affected is characterized by the feeling of being overwhelmed. In this respect, a person's resources (for example, selfawareness, self-efficacy, social skills, self-control, dealing with stress, problemsolving) have an important influence on the positive or negative course of a crisis. Furthermore, coping strategies influence the person's "resistance" to acting stressors and therefore represent a protective factor against the outbreak of crises. Thus, when we ask about the mental health of actors in the music business, it is important to not only consider the pathological perspectives in regards to what stressors contribute to mental illness, but also which resilience factors and strategies for coping with crises are available to them.

Taking Dross's (2001) view into account that crises are characterized by people falling out of the "normality" of their accustomed and reliable everyday selfevidence, it must also be questioned how the self-conception of being a DJ is to be understood. Dross claims that in self-conception, the respective achieved balance 
of a person's inner worlds with the subjectively experienced reality is bundled. In order to understand the experience and behaviour of people, it is therefore necessary to get to know their world of thought. In this context, self-concepts can be understood as self-perceptions based on self-descriptions and self-assessments (Spychiger 2017, 2007). Narratives (in the sense of "the means of human sensemaking" according to Squire 2008: 50) play an important role in the construction of self-perceptions, meaning the perceptions a person may have about themselves. Such points of reference for the emergence of self-concepts can be seen in plots from personal stories (Polkinghorne 1991). If self-narratives provide access to selfreferential information on an individual, and these in turn can be generated by communicated stories, narrative-biographic self-statements can be a key function for the reconstruction of self-concepts, and therefore provide information on how people see themselves, how they experience their version of reality, and how they deal with crisis situations.

Derived from this, the experience and the handling of crises are regarded as part of an entire life story, underlying the individual ideas of the artists themselves but also connecting to inner and external resilience factors and coping strategies. To understand what a DJ suffers from in relation to their expectations of the profession, the self-construction of the person in question has to be considered. When it comes to the inquiry regarding ideas about one's self, the consideration of subjectivity is therefore central. As a (reconstructive) method for collecting self-referential data, a qualitative interview makes it possible to generate narratives and thus produce narrative knowledge. This is also true for the narrative-biographical interview. The narrative interview technique, as developed by Schütze $(1987,1983)$, is used to develop an open form of interview that avoids the limits of standardized surveys by not following the usual question and answer scheme. Rather, the interviewees themselves determine the design of the interview in terms of topic and course. The discussion is intended to imitate everyday communication based on actual action and thus build on the points of view of the interviewees.

During the first lockdown in Germany from June to August 2020, data from fourteen narrative-biographic interviews with DJs were collected in Berlin, Bielefeld, and Duesseldorf. The main selection criterion for the DJs to be interviewed for this study was that they consider themselves as being a DJ and that they are working in the various areas of EDM. The DJs were between 24 and 54 years old at the time of the study and included four female and ten male participants. All interviews were conducted in German; the quoted passages in the following are translated to English, and the names of participants have been anonymized throughout the study. I will use the example of three selected cases to explore the interaction of these individuals with their social environment, as well as subsequent factors influencing their conception of personal wellbeing. The explanations are not intended to be representative results but rather reflect the interpretation of individual perspectives that provide insights into personal life environments and subjective (self-)experiences.

\section{The 'DJ-Self': Case Studies}

\section{Stella}

Stella is a freelance techno DJ in her late thirties. Her path to becoming a full-time DJ has not been linear. As a child, she learned the piano; in her childhood and youth, she was primarily interested in competitive sports, and always wanted to be "the best". The high pressure to perform overwhelmed her and led to burnout. 
Shortly before graduating from high school, she was admitted to a psychiatric clinic for the first time. After school, she decided to study at a renowned private university abroad and got a lucrative, high-paying job. She loved the feeling of power, of being competent. She wanted to fit in and impress people. She loves order, structure, and security. At the same time, she wants to be "cool" and "free" and "not let the system get [her] down". She became particularly aware of these two parts of herself, which she refers to as the head and the gut ego, during a private stay in Australia. She was fascinated by a cool, wild lifestyle she encountered there, which triggered a new zest for life in her. She discovered the rebelliousness in her, which went against her previous life structures that kept her "in line". While working abroad, she got to know a local live music scene. The big city offered her new opportunities to go out in the evenings and opened up previously unknown musical worlds to her. She started an indie band with her boyfriend at the time, in which she played drums. She realized that she could not unite the two "worlds" of being a businesswoman by day and her alternative life at night. She quit her job, attended clubs, and took drugs. When the band broke up, she decided to continue making club music with her boyfriend. After breaking up with her boyfriend, she used her production software skills and started DJing in clubs on her own. She was initially disoriented but quickly found a job and started DJing on the side. When a friend's job offer brought her back to Germany, she let herself drift into the club scene and enjoyed the feeling of "getting lost". Stella experienced the first two years as "mindblowing". She quickly made a name for herself in the scene, and DJing is now her main job. She also realizes that "partying is the marketing of a DJ". Although she enjoys the rush, she also experiences the negative effects of the self-imposed lifestyle - she is often awake for days, taking drugs, drinking alcohol, and chain smoking - and begins to have doubts.

When you party all night, that physicality, you're just weak and sleep deprived. During the weekend everything was always so totally everything pink, Monday and Tuesday then always very grey. And then I hated not being fit. I always wanted both. I wanted freedom and no restrictions, but I couldn't handle the fact that it also had negative consequences. And I had to learn that first. If it's just awesome, then you don't question the consequences.

Stella begins to worry about her health. She has tonsillitis and bronchitis several times a year. She not only realizes the consequences of her unhealthy lifestyle, but she also recognizes an inner emptiness that she tries to numb through the intoxicating club experiences, distracting her from her real problems: "The weekend was like a substitution". The emptiness became especially apparent after the weekends. She decides to start psychotherapy. She reports a shudder at the permissiveness she experiences on weekends, although she is otherwise a very controlled person, always weighing everything and never letting anything get to her. She not only finds it difficult to take the step of seeking help and talking about her problems, she also has little confidence at first that she can overcome them. She nevertheless develops enough willpower to change her lifestyle and stay away from drugs, alcohol, and excessive partying. She also withdraws from her personal life. Isolation becomes the "new normal" for her. The state of sobriety scares her and makes her doubt herself. She describes herself as depressed during this time and is especially burdened by the feeling of not being good enough. After three months, however, she becomes accustomed to the condition and no longer misses losing herself in weekend intoxication. She realizes that she can party all night without alcohol or drugs and that sobriety actually has positive effects on DJing: she feels 
more focused and more "into the music". Until Lockdown in March 2020, she DJs in clubs, working private as well as corporate events, and describes her standard of living as "comfortable".

\section{Gabriel}

Gabriel is in his early thirties and has turned his passion for making music into a profession as a melodic house DJ. He has always been interested in music. After learning the cello and electric bass, he started writing rap lyrics and performed at youth clubs with his first "boyband". After his dream of becoming a "world-class boxer" did not work out, he finished high school and started studying but dropped out after a year. He toof some time off, went partying, and rediscovered his interest in music as well as DJing. He met a DJ who not only introduced him to the techniques of DJing and producing but also brought him into contact with drugs (speed). He began studying musicology and decided to become a DJ and producer. To save rent, he moved in with his grandma, quit his part-time jobs and put everything on the realization of his plan. This time is marked by financial strain, which weighed heavily on him and made him doubt himself. However, when a label signed him, not only did his self-confidence begin to increase, but also his standard of living. He was consistently productive and "flooded the market" with his tracks. After he had his first chart successes on Beatport, he was also booked internationally. He enjoyed the jet-set lifestyle that goes along with his notion of being a DJ and lived a life of "abundance" (dining out, parties, drugs, women) due to the temptation of the money he now earned. He develops compulsive sexual behaviour during this time, which he tried to substitute through increased drug use. He felt more and more uprooted and restless by being on the road all the time, and could no longer keep up with the velocity of his life caused by touring, and fell into a crisis of meaning. His urge to always be "number one" put him under additional pressure; he had the feeling that he had to "deliver". He put his artistic aspirations before his ability to build on earlier successes. When things did not go well for months, he got into financial straits, which was accompanied by uncertainty and caused him to panic. He realized that he did not "want to get lost in the maelstrom of drugs and parties", as was the case with some of his friends and role models. He began to mobilize new willpower and build self-confidence. It is only when he became aware again of his original passion - making music - he managed to overcome his crisis:

I'm at a point now where I'm trying to be an artist on a healthy basis. I try to enjoy it, but of course, I don't want to be a killjoy. I still like to party and go over the top from time to time, but everything has to be done to such an extent that you're happy, you're productive and you can evolve as a musician, as an artist and as a brand.

\section{Alex}

Alex is thirty years old and works as an independent techno DJ. Music has always been important to her. As a young girl, she learned to play the violin before she became interested in heavy metal. She first came into contact with electronic music when she moved from a small town to a big city for her studies and discovered the club scene there. Fascinated by the DJs and LJs (Light Jockeys) in the club, she accepted the opportunity to work as an LJ in the club herself. She met her boyfriend during this time, who was a DJ and introduced her to DJing and producing. She 
became a well-booked DJ but perceived herself primarily as a service provider, which did not do justice to her artistic aspirations behind DJing. She also experienced a stressful imbalance between the highs in the club, when she is cheered, and the phases when she was at home and received no support. Difficulty in planning due to the financial uncertainty of self-employment put her under a lot of stress. With her boyfriend also suffering from burnout, they decided to move to a bigger city that offered them more opportunities. The superficiality in the highly competitive business and the pressure of having to take drugs to be part of the scene led to another low point. After a phase of intense drug use, she feared going in a dangerous direction and distanced herself from the scene. Although she was well booked - even internationally - touring increasingly became an extreme effort due to irregular working hours, lack of sleep, and jet lag. She had to function and be constantly in party mode, even when she did not feel like it: "There's only good or bad, rarely anything in between". Having to constantly acquire new gigs became a major stressor. She further experienced her professional environment as unprofessional and primarily profit-oriented:

For me, it was like, I see very little sense now, it's all built on marketing now anyway, look at this whole Avicii story. So many ghost productions, so much is fake, this social media is so interesting, and partly you realize that it's not the really good people who get on the bandwagon, it's the ones who can just sell themselves well, it's depressing.

During this time she experienced little appreciation from her community, and the stigma of constantly being reduced to her looks and having to prove herself over and over again as a female DJ also made her doubt her profession. Her self-worth declined, and her mental wellbeing became imbalanced. Although she loved DJing and producing, she no longer found joy in her profession and perceived herself as severely depressed. After the club she worked at as resident DJ shut down, she looked for an office job so that she would no longer be financially dependent solely on her DJing activities. By chance, she also got in touch with a self-help group on social media during this time - a platform for female musicians with similar problems. Through the exchange with like-minded people, she has experienced a sense of empowerment. She reflects on her strengths and is now motivated to pursue her path as a DJ and producer. Through new bookings, she gains new selfconfidence.

\section{Resources and Experiences of Crisis}

Stella's example makes it clear that an experience of crisis and the way it is dealt with is shaped both by personality-centered factors and by previous experiences. Stella experiences her first crisis, characterized by overextension and exhaustion, as a teenager. Although she undergoes therapeutic treatment, she repeatedly falls into old patterns and seeks out tasks that correspond to her drive for achievement, success, and recognition. Again and again she experiences a discrepancy between the polarizing needs she feels. She strives for security, control, and structure and at the same time feels a need for freedom, which she can act out, especially in nightlife. She states that she was already extroverted as a child but has developed fears of being herself due to the conditioning she experienced in her childhood. She tries to compensate for these inhibitions by consuming alcohol and drugs in order to repress her introverted part, especially in her role as a DJ. Realizing that "partying 
is the marketing of a DJ", she constantly stays in clubs, so that private partying soon became indistinguishable from her DJ activities. The "ego-boost" she had previously received from her job performance as a business woman, she now receives from the stage. As a DJ, she cannot only pursue her passion for music but also escape from her fears and worries. She is persistently in phase [1] of Kast (2017) and Cullberg (1978) crisis model, characterized by "not wanting to admit". But she realizes that this form of escapism only works temporarily and is not sustainable since the physical effects of excessive partying can no longer be denied. Lack of sleep and increasing speed consumption manifest themselves in avolition, exhaustion, and sickness. Confronted with these physical health problems, she experiences a rupture of her own self-conceptions. The repression of the introverted part leads to an imbalance, which causes discomfort. She feels this especially after weekends ("control-free zone") when she is taken over by regrets. Phase [2] of the crisis experience is characterized by strong emotional reactions. She still does not manage to leave the repression process. She tries to cope with the emotional discrepancy through various self-experiments: she starts excessive sports, replaces speed with cocaine and changes the form of consumption (she swallows the drug instead of snorting). She realizes her problem again but cannot draw on any personal experience to solve it. She has no experience to fall back on except for her toxic coping attempts. She only manages to free herself from this when she accepts that she no longer wants to endure the emptiness she is experiencing, which can be interpreted as a marker for the transition to phase [3]. She begins to reflect intensively on her situation and becomes aware of her strategies of diversion: when she decides to seek therapeutic help and stop using mind-altering substances, she realizes that her previous "world of experience" had been built on states of intoxication. She continues to DJ but is completely overwhelmed. She experiences social anxiety, becomes thin-skinned, and isolates herself. When sober, she can no longer escape from herself. While she wants to do "everything perfectly", she has self-doubt and can no longer cope with the real situation in the club.

The COVID-19 pandemic hits her at a stage when she has already reached the last phase of crisis [4]: she has become accustomed to sobriety and even accepted it as a strength. Her previous crisis experience allows her to draw on experiential strategies that help her navigate the pandemic. She describes three phases she experiences from the lockdown in the interview: the first phase is characterized by immediate action and reorientation. She updates her resume and applies for jobs, immediately adapting to the new situation: "Bam! That was almost a liberation. Okay, new situation, how do I make the best of it. That was cool to feel that [kind of freedom] again". Although she does not get a job offer, she quickly receives financial help from the government. In addition, a friend arranges a part-time job for her. Sober and financially secure, she initially experiences a sense of wellbeing.

I suddenly had the feeling as if the outside world had aligned with my inner world. Everyone keeps their distance, I no longer have to go to the club, everyone leaves me alone. No obligations. Awesome! So, it was just a complete relief. The weather was great, and I went cycling every day, which was really cool. I just let myself drift.

A sense of liberation and an associated light-heartedness is replaced by existential fears in the second phase: "I got so used to it over the years that a booking would come in at any time. And I've always carried this confidence around with me, and now I realize it doesn't work like that, I can't live on a thousand euros a month in the long run, it doesn't work. And then there was a bit of 'Fuck!' again". Above all, 
she realizes that the pandemic could last longer and the precarious financial situation could become permanent. Although she has fears about the future, she characterises phase three with new confidence, in which she holds on to the few opportunities to perform on stage again. Reflecting again about her motives for having become a DJ, she says:

The big advantage of DJing, besides the DJing itself, is the incredible amount of free time you have. I need a lot of time for myself. My biggest inhibition is to look for a job that takes more time because I already realize that everything is resisting. I don't know when the point is reached that it is somehow necessary, but I think something will come. Just don't do a permanent job now.

Self-reflection, optimism, and confidence combined with a high level of selfefficacy become resources that provide her with a sense of wellbeing during this time: "I'm actually doing pretty well. I'm not mourning old things, I don't have melancholy or nostalgia. I don't even really know what it feels like to hang up anymore. I kind of don't miss it either. But if it's back, I'll probably like it again, but it's also okay that it's not there, I don't know".

Gabriel reacts to the early pandemic similar to Stella: "In the beginning, I thought it was great". Neither perceive the onset of the pandemic as a "shock" (phase [1]). He receives financial support from the state and begins to open up new income streams (producing music for commercials, sample packages, remixes). The overwhelming of emotions (phase [2]) does not begin until awareness of potential long-term consequences of the COVID-19 crisis sets in. When it becomes clear to him that the pandemic is not an exceptional short-term situation, he is primarily concerned with fears and existential worries that remind him of crisis situations he already experienced in his early days as a DJ and music producer: "That's when I really started to feel like shit. That's when you're back to being twenty and worrying about money". He experiences that past as particularly stressful. He cannot afford good equipment and puts himself under pressure, which prevents him from making music and leads to self-doubt: "Why am I doing this at all? Am I wasting my time? Why didn't I do what everyone else did? Why did I drop out of university?" He is now in a phase of erupting chaotic feelings (see phase [2]). He experiences his state of crisis not as a sudden event but as a gradual process. With his father's encouragement, however, he becomes aware of his strengths and recalls his decision to be a DJ and producer, as well as the willpower that goes with it: "You can do it! Be patient, that's the process, you have to trust yourself. It's not about making the right decision anymore, it's about making the decision right". Even though this crisis makes him doubt himself at first, he continues to benefit from this belief system: "I know what I can do, I also know how I can achieve certain things, but it's still this voice in the back of my head that says this won't work out, you'll never have another gig".

What makes the current situation different from past crises is that he has recognized his acute problem and can draw on appropriate experiential skills and coping strategies, and henceforth does not experience the COVID-19 crisis as such. In the past, even though he was initially able to overcome phase [2] of the crisis schema, it seems to have solved his actual problem only temporarily. With the first successes of his music, the accompanying flights of fancy displace his fear of emotional and financial insecurity. However, the fast pace of life of a touring DJ makes him lose control. His behaviour, which he himself describes as unprofessional ("you can't just be coked up after your gig when you talk to the promoters"), makes him unhappy. A lack of gigs and chart positions are, in turn, 
the trigger for financial hard times, causing a vicious circle. His behaviour eventually leads to him neglecting the passion that has brought him to this success, as well as the associated "artistic claim". His activities as a DJ and producer are exclusively profit-oriented. In his view, he develops from an artist to a service provider. He falls into what he himself calls a crisis of meaning, a depressive state: "Do I want the success? Do I want this life?" He sees this low point as a necessary and seminal consequence: "I had to fall". From his community, he receives no offers of help; on the contrary, he even believes that the people around him cheered on his toxic, destructive behaviour: "The rock star attitude is part of music history. People love rock star stories. They experience them through you, you're their extension. They don't want to give you advice or question you, they'll rather applaud. Even my manager always celebrated it when I told him stories like that".

The recollection of his past fears triggers a feeling of powerlessness in times of the pandemic. However, it is not only the memories of the past crisis stress that come up, but also how he overcame it: "I didn't really have a strategy there, I just didn't want to 'get lost in the maelstrom of drugs and partying' [...]. If you realized what was wrong, then you can't unsee it anymore, then you will automatically change. I felt like it was in my hands now". In addition to self-discipline, meditation, and self-help literature, his most important crisis management resources were his friends, in whom he confides:

It's important in such moments that you open up, that you show yourself vulnerable, that you also say, hey, I need help, that your environment knows where your weakness is. Then people help you, then you sort of create an environment around you that says no to certain things and advocates and supports other things.

He develops the belief that he can do anything: "Today I know that's not true. In fact, I've also been very lucky. But man forges his own destiny. That idea helped me to keep going." Even though it is always difficult for him to endure the feeling of insecurity and fears during the pandemic ("How long will the money last? What do I do if the scene needs two years to recover? What do I do if it'll never be like before? What do I do if the clubs die?"), he actively approaches problem-solving and accepts the situation. He sees flexibility as his strength in this context:

You have to keep your eyes open to how the market is developing ... OK, the next half year, there will be no gigs. Five years from now, when you look back at that half year, what would be the most important thing you would have done in that half year ... I try as much as possible to push things that result in something in the long run. Because even if I generate the total hype around me now, if I'm the DJ who does the most livestreams and gets the best views on the livestreams, right now nobody can be booked, there are no parties, so what does this hype mean to me right now. So I said to myself, the best thing you can do is make music because then when it starts up again, you'll have thirty new tracks and you'll have become a better artist, and in that time you'll have picked up new skills on it.

He likewise cites meditating regularly and not focusing on the things he has no control over as another strategy for coping with problems: 
I can't control when things will go on, when vaccinations will happen, which clubs will disappear. But I can focus on continuing to be in touch with my agency, motivating them and asking, hey, what are our options? Is there maybe another promoter doing something where I fit in?

By accepting the situation in the course of realization and (re)orientation (phase [3]), he also experiences a new sense of self. He thinks about what is important to him and, in particular, also tries to increase his "human capital":

Building more skills, learning more things, and also doing things I didn't have time for because I was always on the road - like spending more time with my girlfriend on weekends, going on vacation once in a while without any gig attached to it, reading the newspaper, doing research, investing in stocks. I've got my own label in the planning stages now, which I've totally pushed forward within that time.

Alex's example particularly highlights the general potential of crisis experiences. She also falls into a psychological crisis before the pandemic, caused by stressors related to her activities as a DJ. The psychological stressors she experiences from her working conditions and the related lifestyle add up and initiate the first phase of the crisis [1]. She recognizes her problems but represses them or numbs them with the use of drugs. This behaviour, however, leads to high physical and mental exertion and increases the feeling of stress. She wants to get out of this phase but initially reacts emotionally and bottles up her feelings. She does not find effective coping strategies, which leads to aimlessness and loss of motivation. She begins to isolate herself from her social environment, which indicates the transition to phase [2] of the crisis model. Alex feels burned out and exhausted. She keeps questioning the point of her activities and reflects on her perspectives for the future. Her daily routines shortly before the beginning of the pandemic are a constant struggle.

It was really difficult for me to put my mental wellbeing on a decent level. I just bottled everything up and talked to no one about it. I had entire evenings where I was just quiet and completely drained. I don't know if that was a small depression. I really considered just stopping everything, I didn't want to play music, I'd do a normal job without stress. And then Corona happened. At first, everything's going well and you've got enough money to save a bit, and then Corona happens and it's all gone.

The loss of a lucrative job and the associated financial loss prompt her to look for a part-time job outside her usual work environment. At first, she has to come to terms with the new work situation. Even though she initially perceives this "separation" and "(re)orientation" (phase [3]) as a crisis of meaning - since her selfconcept of wanting to be a DJ not only falters, but she fundamentally questions it she experiences the additional source of income as a liberating component that offers her financial security and more flexibility for her artistic activities. With the onset of the pandemic, however, her last gigs and employment opportunities as a DJ now also fall away, which reinforces her crisis of meaning and the feeling of financial insecurity. Due to the fact that she was already in a state of permanent self-reflection before the pandemic, coming to terms with the crisis situation is not a completely new experience. However, the feeling that she is "losing the ground beneath her feet" initially puts her back into phase [1] in her ongoing crisis process. Together with her partner, she regularly smokes weed to escape negative thoughts. Alex's partnership becomes a supportive basis that gives her stability in times of 
crisis. Together they are searching (phase [2]) for strategies to solve their situation. While they do try to motivate each other, it is hard for both to remain confident and find solutions: "Of course you can create content, but you have to be creative, motivated, rested, and fit for that. If you've got all these existential fears, that's rather counterproductive". The constant insecurity does not let them rest:

\begin{abstract}
You know things will work out eventually. That means you have to prepare, you have to pre-produce tracks, you still have to somehow connect with people, you still have to be active and interesting for promoters and eventers. On the other hand, nobody really cares what's going on at the moment. So there's this constant tug of war between: 'OK, when can I chill out', and: 'OK, stuff keeps going, people still need content, you gotta stay visible, what do you post as a DJ during Corona if you don't have gigs'.
\end{abstract}

It is only through the self-help group that she is able to change her own expectations about her life and profession and to think about what is really important to her. She interprets her reaching out for help as a positive result of the crisis and has vowed to emerge from it invigorated in spite of all setbacks. Similar to Gabriel, having learned to "vent", to speak about her fears and worries, she is beginning to use the time productively. Even though she does miss playing and especially the contact with the audience, she has begun working on new tracks, repairing old recording devices, and preparing a shop for her merch. She increasingly experiences the crisis as a creative turning point: "So much is happening, people are trying to get things started, doing new collaborations, to really create something new. Things are growing, and there are a lot of ideas". The crisis she overcame leads to mental strengths and wellbeing, as Kast (2017) also describes for phase [4] of "(re)orientation". Similar to Tedeschi et al.'s (2018) formulation in the course of "posttraumatic growth" theory, the crisis leads, in her case, to an intensification in the appreciation for life and a trigerring of the maturation process from the traumatic experience, resulting in a change in priorities. It is precisely through the awareness and acceptance of her own vulnerability that the sense of inner strength also grows. Even though the future feels uncertain and she has no clear idea of how and when things will continue, she, like Gabriel, has great confidence that things will continue - and she wants to be as prepared as possible for it.

\title{
Conclusion
}

Although the pandemic can be considered a global crisis, crisis experiences of each individual depend on personal evaluation criteria. Various motives and expectations transform the perception of mental strains and are subject to dynamics of change. Besides the fact that the interviews do not provide a representative sample, the results confirm the findings of the Help Musicians report (2021) introduced at the beginning of this article, in that the pandemic represents a stressful phase of life for all study participants in terms of their mental health, including concerns about the future, self-doubt, and insecurity. Existential fear seems to greatly burden all respondents. This means not only includes the fear of no longer being a DJ due to the lack of visibility and imminent cultural irrelevance in the scene; in particular, financial fears are cited due to lack of bookings and uncertainty about future employment. The fact that financial fears are a heavy burden for many (especially self-employed) DJs is not limited to the COVID-19 crisis. Also validating the findings of the earlier Help Musicians report (Gross and Musgrave 2016), the study shows that it is not only the virus-related crisis situation that leads to mental 
challenges of the interviewees; the three cases illustrate that even before the pandemic, mental health concerns in different contexts were already an issue and caused by various factors, sometimes related to the career choice and the associated lifestyle. Again, it becomes clear that the experience of supposed stress factors related to the life as a DJ is subjectively constructed and (at different times) depends on the individual biological and psychological factors (vulnerability factors) as well as environmental factors (psychosocial risk factors).

Besides - or even because of - the challenges the interviewees have to face, they try to utilise the resources resulting from the crisis to their advantage. The process of dealing with the prevailing circumstances of life offers the possibility for selfreflection about their chosen DJ profession, and thus the opportunity for change, focusing on a fundamental improvement of a given life situation. All respondents (subconsciously) have developed strategies for maintaining or appropriating their mental resilience. In this case, the results of the study are not consistent with current research. According to the Help Musicians 2021 report, four in five of those experiencing mental health problems (eighty-one percent) say they do not get the professional help they need. The fact that it is obviously difficult for artists in general to find help becomes more clear in the context of the pandemic. There seem to be enormous challenges on the health care side. Despite existing aid measures and treatment programs such as Help Musicians, MusiCares or Backline, musicians in need of mental health support are confronted with the limits of mental health services. As the results of Record Union's survey have already shown in 2019, of those musicians who said they had suffered from symptoms of mental illness, only thirty-nine percent said they had sought out treatment for their symptoms, and fiftyone percent had self-medicated, the majority of which with alcohol and drugs. This kind of coping strategy was also mentioned by most of the fourteen interviewees within this study, in response to any crisis they experience within the profession of being a DJ.

Although the interviewees at the time of the interviews accept the situation in the course of realization and (re)orientation and strive to assess the situation positively, the study raises general questions about what the music industries and academia can do to establish a duty of care and (financial) security for those working within it. As mentioned earlier, from a person-centered perspective, it is clear that the respondents fall into crises due to incongruence between their personal experiences and self-concepts. From a systemic perspective, however, the crisis affects not only each individual, but the entire system. Appropriate measures such as financial security, basic income, counseling, promotion of knowledge about mental health, and therapy - as acknowledged by Gross et al. (2018) and Gross and Musgrave (2020) - must also be accompanied by a fundamental change in the music industries.

\section{Endnotes}

(1) EDM is used as an umbrella term here, encompassing all forms of Electronic Dance Music (cf. Mazierska et al. 2021; Jyri 2021; Feser and Pasdzierny 2016). 


\section{References}

\section{Bibliography}

Academy of Science of South Africa and German National Academy of Sciences Leopoldina 2020. The Hidden Crisis: Mental Health in Times of Covid-19. Proceedings Report.

https://www.leopoldina.org/uploads/tx_leopublication/2021_ASSAfLeopoldina_Mental_Health_COVID_final_01.pdf. Accessed: 30. May 2020.

Association for Electronic Music, Music Managers Forum, Help Musicians UK, and Music Support 2019. The Electronic Music Industry Guide to Mental Health. https://www.associationforelectronicmusic.org/afem-mental-healthguide-for-the-electronic-music-industry. Accessed: 18. October 2020.

Bloomberg 2020. Covid-19 Pandemic Most Challenging Crisis Since World War II: UN Chief. https://www.bloombergquint.com/coronavirus-outbreak/covid19pandemic-most-challenging-crisis-since-world-war-ii-un-chief. Accessed: 18. October 2020.

Brewster, B. and Broughton, F. 2006. Last Night a DJ Saved My Life: The History of the Disc Jockey. London: Headline.

Brunt, S. and Nelligan, K. 2020. The Australian music industry's mental health crisis: media narratives during the coronavirus pandemic. Media International Australia 178(1): 42-46.

Cloonan, M. 2014. Musicians as workers: Putting the UK musicians' union into context. MusiCultures 41(1): 10-29.

Cullberg, J. 1978. Krisen und Krisentherapie. Psychiatrische Praxis 5: 25-34.

Dross, M. 2001. Krisenintervention. Göttingen: Hogrefe.

Feser, K. and Pasdzierny, M. Eds. 2017. Techno Studies: Ästhetik und Geschichte der elektronischen Tanzmusik. Berlin: b_books.

Filipp, H.S. 1997. Kritische Lebensereignisse. München: Urban and Schwarzberg.

Gross, S. et al. 2018. Well-being and mental health in the gig economy. Policy perspectives on precarity. London: University of Westminster Press.

Gross, S. and Musgrave, G. 2020. Can Music Make You Sick? Measuring the Price of Musical Ambition. London: University of Westminster Press.

Gross, S. and Musgrave, G. 2016. Can Music Make You Sick? Music and Depression. A Study into the Incidence of Musicians Mental Health. Part 1Pilot Survey Report. Harrow: MusicTank.

Help Musicians 2021. Hidden Mental Health Crisis amongst musicians [press release]. https://www.helpmusicians.org.uk/news/latest-news?page=view-all Accessed: 15 June 2021.

Hesmondhalgh, D. and Baker, S. 2011. Creative Labour: Media work in three cultural industries. New York: Routledge.

Hope, S. and Richards, J. 2015. Loving Work: Drawing Attention to Pleasure and Pain in the Body of the Cultural Worker. European Journal of Cultural Studies 18(2): 117-141.

Hughes, D. et al. 2016. The New Music Industries: Disruption and Discovery. Cham: Palgrave Macmillan.

Jóri, A. 2021. The meanings of "Electronic Dance Music" and "EDM". In E. Mazierska, L. Gillon and Rigg, T. Eds. The Evolution of Electronic Dance Music. London: Bloomsbury Academic: 25-40. 
Kast, V. 2017. Der schöpferische Sprung: Vom therapeutischen Umgang mit Krisen. Düsseldorf: Patmos.

Lazerus, R.S. 1999. Stress and Emotion. A new Synthesis. London: Free Association Books.

Leff, J. 2020. Caring for our health. Winter Jazzfest Official Program Guide 5.

Mazierska, E. et al. Eds. 2021. The Evolution of Electronic Dance Music. London: Bloomsbury Academic.

McRobbie, A. 2016. Be Creative. Making a Living in the New Culture Industries. Cambridge: Polity Press.

Musgrave, G. 2020. Avicii: True Stories - Review. Dancecult: Journal of Electronic Dance Music Culture 12(1): 94-97.

Polkinghorne, D.E. 1991. Narrative and Self-Concept. Journal of Narrative and Life History 1(2,3): 135-153.

Ptatscheck, M. 2021. Avicii and Mental Health of EDM Stars. In E. Mazierska, L. Gillon and Rigg, T. Eds. The Evolution of Electronic Dance Music. London: Bloomsbury Academic: 105-123.

Record Union, 2019. The 73 percent report. https://www.the73percent.com/Record_Union-The_73_Percent_Report.pdf Accessed: 5 January 2020.

Reiter, L. and Strotzka, H. 1977. Systemische Krisenintervention. Tübingen: DGVT Verlag.

Sample, I. 2020. Covid poses 'greatest threat to mental health since second world war'. The Guardian. https://www.theguardian.com/society/2020/dec/27/covidposes-greatest-threat-to-mental-health-since-second-worldwar?CMP=fb_gu\&utm_medium=Social\&utm_source=Facebook\&fbclid=IwAR3 uhNJclzSa97I-ey5nJZReTauvlqIRxfi-

Fil3ROrIW5btHfkquxAosS0\#Echobox=1609143617 Access: 1 January 2021.

Sandoval, M. 2018. From passionate labour to compassionate work: cultural coops, do what you love and social change. European Journal of Cultural Studies 21 (2): 113-129.

Schott, L. 2019. Mental health problems in the harder styles scene: "You have everything people wish for, but you still feel like this". HardNews. https://www.hardnews.nl/en/mental-health-problems-in-the-harder-stylesscene-you-have-everything-people-wish-for-but-you-still-feel-like-this/ Accessed 18 October 2020.

Schütze, F. -

1983. Biographieforschung und narratives Interview. Neue Praxis 3: 283-293.

1987. Das narrative Interview in Interaktionsfeldstudien: Erzähltheoretische

Grundlagen. Hagen: Studienbrief.

Simmich, T. et al. 1999. Empfehlungen zur Behandlungspraxis bei

psychotherapeutischen Kriseninterventionen. Psychotherapeut 44 (6): 394-398.

Spychiger, M. -

2007. 'Nein, ich bin ja unbegabt und liebe Musik' Ausführungen zu einer mehrdimensionalen Anlage des musikalischen Selbstkonzepts. Diskussion Musikpädagogik 33: 9-20.

2017. From musical experience to musical identity: musical self-concept as a mediating psychological structure. In MacDonald, R.A.R., Hargreaves, D.J. and Miell, D. Eds. Handbook of Musical Identities. New York: Oxford University Press: 288-303. 
Squire, C. 2008. Experience-centered and Culturally-oriented Approaches to Narrative. In Andrews, M., Squire, C. and Tamboukou, M. Eds. Doing Narrative Research. Los Angeles: Sage: 41-63.

Strong, C. et al. 2020. The Victorian Music Business Career Life Cycle. Melbourne, Australia: RMIT University for the Victorian Music Development Office.

https://static1.squarespace.com/static/5b88e39855b02ce9bc082fcf/t/5e5455fd2 722a6617e7ea68b/1582585405092/Career+Paths+-

+ The+Victorian+Music+Business+Career+Life+Cycle.pdf. Accessed: 30 May 2021.

Tedeschi, R.G. et al. 2018. Posttraumatic Growth: Theory, Research, and Applications. New York and London: Routledge.

Weik, K.E. 1988. Enacted sensemaking in crisis situations. Journal of Management Studies 25: 305-317.

\section{Videography}

Avicii: True Stories. 2017. Dir. Levan Tsikurishvili. Piece of Magic Entertainment/Black Dalmatian Films/SF Bio. https://www.bbc.co.uk/programmes/p075zdlk. Accessed: 29 October 2020.

Pioneer DJ 2020. Distant Dancefloors: Covid-19 and the Electronic Music Industry. https://www.youtube.com/watch?v=OphRF8vfOzo Accessed: 18. October 2020. 